travenous L-DOPA plus carbidopa in depressed patients: Average evoked response, learning and behavioral changes. Psychosom Med 38:95-105.

Onofrj N, Bodis-Wollner I (1982): Dopaminergic deficiency causes delayed visual evoked potentials in rats. Ann Neurol 11:484-490.

Schildkraut JJ, Kety SS (1967): Biogenic amines and emotion. Science 156:21-30.
Skala H, Holman J (1984): Effect of pupillary dilatation in flash VER recording. Doc Ophthalmol 63:321-324.

Tukey JW (ed) (1987): Exploratory Data Analysis. Reading, MA: Addison-Wesley.

Yaar I (1980): The effect of levodopa treatment on the visual evoked potentials in parkinsonian patients. Electroencephalogr Clin 50:267-274.

\title{
Positive and Negative Symptoms in Schizophrenia and the Dexamethasone Suppression Test
}

\author{
Rajiv Tandon, Kenneth R. Silk, John F. Greden, Joann Goodson, \\ M. Hariharan, James H. Meador-Woodruff, and Ziad Kronfol
}

\section{Introduction}

Although the Dexamethasone Suppression Test (DST) was originally proposed as a specific marker for major depressive disorder (Carroll et al. 1981), several recent studies have reported high rates of DST nonsuppression in schizophrenic patients, ranging from $22 \%$ to $73 \%$. DST nonsuppression in schizophrenia has been attributed to depressive symptomatology (Munro et al. 1983), negative symptomatology (Coppen et al. 1983; Shima et al. 1986), subtype differences (Banki et al. 1984), episodic course, and good prognosis (Targum 1983). Investigations have so far yielded discrepant findings, prompting at least one author (Myers 1984) to suggest

\footnotetext{
From the Schizophrenia Program, University of Michigan Medical Center, Ann Arbor, MI.

Address reprint requests to Dr. R. Tandon. Director, Schizophrenia Program, UH-9C-9150, University of Michigan Medical Center, Box 0120, 1500 E. Medical Center Drive, Ann Arbor, MI 48109. Presented at the annual meeting of the Society of Biological Psychiatry, Montreal, May 1988.

Received July 29, 1988; revised September 10, 1988.
}

that DST nonsuppression in schizophrenia is a random event. The present study was conducted to investigate the relationship of symptomatology (depressive, positive, negative) and clinical phase to the DST response.

\section{Methods}

The sample consisted of 20 consecutively hospitalized patients who were admitted to the Inpatient Schizophrenic Program at the University of Michigan. All patients met DSM-III-R criteria (American Psychiatric Association 1987) and Research Diagnostic Criteria (RDC) (Spitzer et al. 1978) for schizophrenia. Informed consent for participation in the study was duly obtained. Patients with organic brain disorder, somatic disease, or alcohol or other substance abuse in the preceding 6 months, or any of the medical exclusion criteria for a valid DST (Carroll et al. 1981), were excluded. The sample consisted of 12 men and 8 women with a mean age of 28.7 years (range 20-45) and a mean duration of 
illness of 5.6 years (range 1-15 years). Patients were maintained in a drug-free state for 2 weeks, during which weight constancy was carefully monitored. A 1-mg DST was performed at baseline (after patient had been medication-free for at least 2 weeks) and was repeated after about 4 weeks of treatment with clinically determined doses of haloperidol, thiothixene, or thorazine singly, or in combination with $2-6 \mathrm{mg}$ of trihexiphenidyl. The test was performed by administration of $1 \mathrm{mg}$ of dexamethasone in tablet form at 11:00 PM and collection of blood samples for analysis of cortisol levels at 4:00 PM and 11:00 PM the next day. Cortisol levels were assayed by Murphy's competitive protein-binding method (Murphy 1967). Maximal postdexamethasone cortisol levels of $>5 \mu \mathrm{g} / \mathrm{dl}$ were considered to be indicative of nonsuppression.

Patients were rated (all by R.T.) on the Brief Psychiatric Rating Scale (BPRS) (Overall 1984), Scale for the Assessment of Negative Symptoms (SANS) (Andreasen 1982), and the 17-item Hamilton Rating Scale for Depression (HRSD) (Hamilton 1960) at baseline and after about 4 weeks of neuroleptic treatment. Clinical ratings and the corresponding DST were performed within a day of each other. The rater was blind to all DST results. Global clinical assessment was done by the 18-item BPRS total score. Positive symptoms were assessed by the sum of the following 7 BPRS items: conceptual disorganization, mannerisms and posturing, hostility, suspiciousness, hallucinatory behavior, unusual thought content, and excitement. Negative symptoms were assessed by the SANS, with the sum of global scores being employed for analysis. Depressive symptoms were assessed by the sum of the 17-item HRSD. Comparisons of demographics and rating scale scores between the initial (baseline) nonsuppressors and suppressors were made by the two-tailed Students $t$ test.

\section{Results}

Seven of the 20 patients were nonsuppressors at baseline. Baseline suppressors and nonsuppressors are compared on various clinical and other parameters in Table 1. The two groups did not differ with regard to age, sex distribution, or total duration of illness. Nonsuppressors had a shorter duration of current psychotic exacerbation (from the time of reported onset of current exacerbation to the time of admission). The two groups did not differ with regard to baseline or posttreatment global severity, positive symptoms, or depressive symptoms. Initial DST nonsuppression was associated with improvement in negative symptoms with treatment (SANS $_{\text {initial }}$ - SAN$S_{\text {postreatment }}$ ), improvement in global severity with treatment (assessed by change in BPRS), and showed a trend toward significant association with baseline negative symptoms. There was no association with change in positive or depressive symptoms. All seven initial nonsuppressors had normalized or become DST suppressors following neuroleptic treatment, whereas all initial suppressors remained suppressive.

There was a significant correlation between baseline negative symptoms and maximal postdexamethasone cortisol levels $(r=0.59, \mathrm{n}=$ $20, p<0.01$ ). There was no significant relationship between maximal postdexamethasone cortisol levels and positive symptoms, global severity, or depressive symptoms at baseline or 4 weeks following neuroleptic treatment. In the posttreatment phase, the correlation between negative symptoms and postdexamethasone cortisol levels was also not significant $(r=0.13$, $\mathrm{n}=20$, NS).

Although all patients were drug-free for at least 2 weeks before the initial DST, Kraus et al. (1988) suggest that withdrawal of neuroleptics and antiparkinsonian agents may produce DST nonsuppression lasting up to 21 days. Analysis of the data to examine this possibility revealed that 10 patients had been drug-free for more than 1 month prior to the initial DST; of these, 6 were DST nonsuppressors at baseline. Only 1 of 10 patients drugfree for less than a month was an initial nonsuppressor. Thus, psychotropic withdrawal effects did not account for the initial DST nonsuppression noted in our study. 
Table 1. Comparison of Initial DST Suppressor and Nonsuppressor Groups

\begin{tabular}{lrr}
\multicolumn{1}{c}{ Parameter } & $\begin{array}{c}\text { Suppressors } \\
(\mathrm{n}=13)\end{array}$ & $\begin{array}{c}\text { Nonsuppressors } \\
(\mathrm{n}=7)\end{array}$ \\
\hline Age duration & $28.5 \pm 6.3$ & $29.2 \pm 4.1$ \\
$\quad$ Illness (years) & $5.2 \pm 2.0$ & $6.3 \pm 4.2$ \\
Current exacerbation (weeks) & $21.4 \pm 21.2$ & $6.6 \pm 4.2^{\circ}$ \\
Maximal post-DEX cortisol ( $\mu \mathrm{g} / \mathrm{dl})$ & & \\
$\quad$ Initial & $2.3 \pm 0.89$ & $10.2 \pm 3.6^{6}$ \\
Posttreatment & $1.6 \pm 0.46$ & $1.8 \pm 0.91$ \\
Depression (HRSD) & & \\
Initial & $10.2 \pm 4.7$ & $11.4 \pm 4.0$ \\
Posttreatment & $7.0 \pm 3.2$ & $7.6 \pm 2.6$ \\
Change & $3.2 \pm 2.1$ & $3.8 \pm 2.9$ \\
Positive symptoms (BPRS subscale sum) & & \\
Initial & $22.7 \pm 5.4$ & $22.7 \pm 5.3$ \\
Posttreatment & $12.8 \pm 6.3$ & $11.1 \pm 5.0$ \\
Change & $9.9 \pm 5.3$ & $11.6 \pm 7.5$ \\
Negative symptoms (SANS global sum) & & \\
Initial & $13.8 \pm 3.9$ & $16.1 \pm 2.8^{\circ}$ \\
Posttreatment & $9.3 \pm 4.4$ & $7.7 \pm 2.9$ \\
Change & $4.5 \pm 2.1$ & $8.4 \pm 1.9^{\circ}$ \\
Global severity (BPRS sum) & & \\
Initial & $47.4 \pm 14.9$ & $51.7 \pm 10.2$ \\
Posttreatment & $26.1 \pm 6.5$ & $24.5 \pm 5.4$ \\
Change & $21.3 \pm 7.1$ & $27.2 \pm 6.2^{b}$ \\
\hline
\end{tabular}

All values are expressed as means \pm standard deviation.

${ }^{a} p<0.10$.

${ }^{b p} p<0.05$.

${ }^{\prime} p<0.01$.

\section{Discussion}

Thirty-five percent of the schizophrenic patients in our sample were DST nonsuppressors at medication-free baseline (a figure intermediate between the $0 \%$ to $73 \%$ rates reported in literature); however, 4 weeks after neuroleptic treatment, all 20 patients in our study were DST suppressors. This finding is consistent with recent reports of DST nonsuppression in the acute phase of schizophrenic illness, with normalization following resolution of acute symptoms (Baumgartner et al. 1986; Moller et al. 1986; Wik et al. 1986; Holsboer-Trachsler et al. 1987). Our finding of an association between initial DST nonsuppression and acuteness of current psychotic exacerbation lends additional support to this linkage. Assessment at different clinical stages of schizophrenia and variable medication status may partially explain the discrepancies in rates of DST nonsuppression reported in schizophrenia; a literature review reveals that investigations of medication-free schizophrenic patients with an acute exacerbation found higher rates of DST nonsuppression than studies of neuroleptic-stabilized chronic schizophrenic patients.

Initial DST nonsuppression was significantly associated with improvement in negative symptoms with neuroleptic treatment and showed a trend toward association with baseline negative symptoms. Postdexamethasone cortisol levels were significantly correlated with negative symptoms at baseline, although this association was not observed after 4 weeks of neuroleptic treatment. Thus, the finding of an association between negative symptoms and DST nonsuppression at drug-free baseline was lost in the posttreatment phase. As with rates of DST nonsuppression, variable clinical phase and medication status may partially account for dis- 
parate findings with regard to the relationship between DST nonsuppression and negative symptoms in schizophrenia.

DST nonsuppression was associated with greater clinical improvement after 4 weeks of neuroleptic treatment, in agreement with reports that suggest that DST nonsuppression in schizophrenia predicts a better outcome of the index episode (Targum 1983). Acuteness of onset and good outcome are considered to be distinguishing features of affective disorders. The association of DST nonsuppression with these clinical variables may be viewed as indicating that depression may be related to DST nonsuppression in schizophrenia; however, no such association was noted in our study. Based on the similarity between the behavioral profile produced by cholinergic overdrive to the negative schizophrenic syndrome (Greden et al. 1988), response of negative symptoms to anticholinergic treatment (Tandon et al. 1988), sleep EEG, and other data (Tandon and Greden 1988a), cholinergic hyperactivity has been proposed as a possible mechanism in the production of negative schizophrenic symptoms. As cholinergic hyperactivity is associated with DST nonsuppression (Carroll et al. 1980), the association of DST nonsuppression with negative symptoms may provide support for the cholinergic excess hypothesis of negative symptoms (Tandon and Greden 1988b). Alternatively, DST nonsuppression in the acute phase of the illness may represent a nonspecific response to stress. This would not, however, account for the relationship between DST nonsuppression and negative symptoms.

Differences in clinical phase of assessment and medication status may explain the widely discrepant rates of DST nonsuppression and variable association of this finding with negative symptoms in schizophrenia. The precise mechanism of DST nonsuppression in schizophrenia is unclear and remains to be evaluated.

\section{References}

American Psychiatric Association (1987): Diagnostic and Statistical Manual of Mental Disorders, ed
3: Revised (DSM-III-R). Washington, DC American Psychiatric Association.

Andreasen NC (1982): Negative symptoms in schizophrenia. Definition and reliability. Arch Gen Psychiatry 39:784-788.

Banki C, Arato M, Rihmer Z (1984): Neuroendocrine differences among subtypes of schizophrenic disorder? Neuropsychobiology 11:174-177.

Baumgartner A, Graf K-J, Kurten I (1986): Serial Dexamethasone Suppression Tests in psychiatric illness: Part I. A study in schizophrenia and mania. Psychiatry Res 18:9-23.

Breier A, Wolkowitz OM, Doran AR, et al (1987): Neuroleptic responsivity of negative and positive symptoms in schizophrenia. Am $J$ Psychiatry 144:1549-1555.

Carroll BJ, Greden JF, Haskett RF, et al (1980): Neurotransmitter studies of neuroendocrine pathology in depression. Acta Psychiatr Scand Suppl 280:183-199.

Carroll BJ, Feinberg M, Greden JF, et al (1981): A specific laboratory test for the diagnosis of melancholia. Arch Gen Psychiatry 28:15-22.

Coppen A, Abou-Saleh M, Milln P, et al (1983): Dexamethasone Suppression Test in depression and other psychiatric illness. $\mathrm{Br} J$ Psychiatry 142:498-504.

Greden JF, Tandon R, Haskett RF (1988): Behavioral effects of physostigmine in normal subjects: Possible model for negative schizophrenic symptoms. (Submitted for publication.)

Hamilton M (1960): Development of a scale for primary depressive illness. Br J Soc Clin Psychol 6:278-296.

Holsboer-Trachsler E, Buol C, Wiedemann K, Holsboer F (1987): Dexamethasone Suppression Test in severe schizophrenic illness; effects of plasma dexamethasone and caffeine levels. Acta Psychiatr Scand 75:608-613.

Kraus RP, Graf P, Brown M (1988): Drugs and the DST: Need for a reappraisal. Am $J$ Psychiatry 145:666-674.

Moller HJ, Kissling W, Bottermann P (1986): The Dexamethasone Suppression Test in depressive and schizophrenic patients under controlled treatment conditions. Eur Arch Psychiatr Neurol Sci 235:263-268.

Munro JG, Hardiker TM, Leonard DP (1983): The Dexamethasone Suppression Test in residual schizophrenia with depression. Am J Psychiatry 141:250-252.

Murphy BE (1967): Some studies of the protein-binding of steroids and their application to the routine 
micro and ultra-micro measurement of various steroids in body fluids by competitive protein-binding radioassay. I Clin Endocrinol Metab 27:973990.

Myers ED (1984): Serial Dexamethasone Suppression Tests in male chronic schizophrenic patients. Am J Psychiatry 141:904-905.

Overall JE (1984): The Brief Psychiatric Rating Scale in psychopharmacology research. In Pichot $\mathrm{P}(\mathrm{ed})$, Pharmacopsychiatry. Basel: Karger, pp 6778.

Shima S, Kitamura T, Takahashi Y, Asai M (1986): Dexamethasone Suppression Test and negative symptoms of schizophrenics. Keio J Med 35:203207.

Spitzer RL, Endicott J, Robins E (1978): Research Diagnostic Criteria: Rationale and reliability. Arch Gen Psychiatry 35:773-782.

Tandon R, Greden JF (1988a): Cholinergic excess and the negative syndrome. In Greden JF, Tan- don R, Pathophysiology of Negative Schizophrenic Symptoms. 141st annual meeting of the American Psychiatric Association, Montreal.

Tandon R, Greden JF (1988b): Cholinergic hyper activity and negative schizophrenic symptoms: A model of cholinergic/dopaminergic interactions in schizophrenia. Arch Gen Psychiatry (in press).

Tandon R, Greden JF, Silk KR (1988): Treatment of negative schizophrenic symptoms with trihexiphenidyl. J Clin Psychopharmacol 8:212215.

Targum SD (1983): Neuroendocrine dysfunction in schizophreniform disorder: Correlation with sixmonth clinical outcome. Am J Psychiatry 140:309313.

Wik G, Wiesel F-A, Eneroth P, et al (1986): Dexamethasone Suppression Test in schizophrenic patients before and during neuroleptic treatment. Acta Psychiatr Scand 74:161-167.

\section{Normal P300 in Acute Schizophrenics During a Continuous Performance Test}

\section{Michael Wagner, Gabriele Kurtz, and Rolf R. Engel}

\section{Introduction}

Evidence from many studies indicates that the vigilance deficit tapped by a visual continuous performance test (CPT) may be a promising vulnerability marker of schizophrenia (Nuechterlein 1985). A reduced $P 300$ component of the cortical event-related potential (ERP) in schizo-

From the Psychiatric Hospital, University of Munich, Federal Republic of Germany.

Address reprint requests to Michael Wagner, Psychiatric Hospital, University of Munich, Nußbaumstraße 7, 8000 München 2, Federal Republic of Germany.

Received February 20, 1988; revised September 13, 1988. phrenics has been reported almost consistently and is considered to be related to such attentional impairments (Pritchard 1986). So far, only Pass et al. (1980) have recorded ERPs of schizophrenics during the CPT. They also found a smaller P300 amplitude in acute psychotic patients. Wc obtaincd contrasting results in a similar study.

\section{Methods}

Fourteen inpatients meeting DSM-III criteria for schizophrenia ( 9 men) were studied. Their ages ranged from 18 to 37 years (mean age 25 , SD 